Arteterapia. Papeles de arteterapia y educación para inclusión social ISSN-e 1988-8309

http://dx.doi.org/10.5209/ARTE.57561

\title{
Terapias de expresión artística a través de la instalación
}

\author{
Eva Muñoz Guinea ${ }^{1}$
}

Recibido: 12 de enero de 2017/ Aceptado: 23 de julio de 2017

Resumen. La instalación como vía de expresión híbrida en la que se contempla la utilización del espacio con un sentido de intervención creativa, - arquitectura, pintura, escultura, fotografía, vídeo, performance, danza, dramatización y música- entre otras disciplinas implicadas, proporciona al campo de la terapia un universo sensorial y proposicional que puede tomarse como base conceptual en el proceso terapéutico mediante las artes.

Partiendo del análisis sobre aspectos conceptuales y artistas de referencia de la instalación y tomando en consideración aspectos pertenecientes a terapias de expresión artística, se plantean sesiones arteterapéuticas fundamentadas en el uso de la instalación.

Palabras clave: Terapias de expresión artística; instalación; arteterapia; hibridación artística.

\section{[en] Expression Therapies Through Installation}

Abstract. The hybrid installation as a means of expression in which the use of space is viewed with a sense of creative intervention, - architecture, painting, sculpture, photography, video, performance, dance, drama and music- among other disciplines, provides to the field of therapy a sensory and propositional universe that can be taken as conceptual basis in the therapeutic process through the arts.

Based on the analysis of conceptual aspects and reference artists of the installation and taking into consideration aspects pertaining to therapies of artistic expression, there are art-therapeutics sessions based on the use of the installation.

Keywords: Therapies artistic expression; installation; art therapy; artistic hybridization.

Sumario: 1. Terapias de expresión artística e instalación. 2. La instalación: El usuario dentro de la obra. 3. Sinergias entre instalación y terapias de expresión. 4. Conclusiones. 5. Referencias bibliográficas.

Cómo citar: Muñoz Guinea, E. (2017). Terapias de expresión artística a través de la instalación, en Arteterapia. Papeles de arteterapia y educación para inclusión social 12, 45-60.

Profesora en Postgrado Salud mental infanto-juvenil Facultad de Psicología (Universidad de Valencia) y profesora en Máster Universitario en Musicoterapia (Universidad Católica de Valencia San Vicente Mártir).

Email: eva.munoz@ucv.es 


\section{Terapias de expresión artística e instalación.}

La instalación como punto de encuentro y catalizador de comportamientos artísticos puede ofrecer herramientas creativas, constructivas y simbólicas al ámbito de las terapias de expresión artística. A este respecto, como mediador terapéutico, López (2011) menciona técnicas y recursos utilizados en los procesos arteterapéuticos y destaca un amplio abanico de posibilidades:

El arteterapia ha sabido adaptar tradición e innovación poniendo a disposición del arteterapeuta múltiples técnicas, materiales y recursos en sus intervenciones: De las clásicas como el Dibujo, Pintura, Escultura o Estampación hasta las más modernas y actuales: Assemblage, Collage, Fotografía, Vídeo, Hibridaciones y Poéticas de Intervención como el Land-Art, Body-art, Instalaciones, Performances, Acciones, Happening, etc.(p.184).

Desde el concepto de Obra de Arte Total definido por Richard Wagner, el Nuevo Teatro de Appia y Gordon Graig hasta Fluxus e Intermedia, las formas de arte se han conjugado, difuminándose así las fronteras entre disciplinas para formar una obra de arte globalizadora. El happening, la performance, el media art, el video art, la videoinstalación y la instalación, son comportamientos artísticos que han negado el valor del objeto artístico museístico y han dotado al espectador de un papel activo en el proceso de creación y percepción de la obra de arte. Estas nuevas formas se producen y suceden desde una óptica que oscila desde la intervención, la interacción o la multisensorialidad.

La instalación está conceptualizada como una intervención espacial en la cual el usuario está, percibe o manipula, en un lugar acotado para ello y en un tiempo o un momento, como "lugar de acción ininterrumpida" (Kabakov, 2014, p.14). El espacio se configura con respecto a nuestra percepción y el acontecer transcurre en el tiempo que permanecemos en ella. El objeto artístico pasa a ser espacio compositivo, en ella cualquier medio puede ser utilizado; esto hace de esta disciplina híbrida, en un contexto terapéutico expresivo-creativo, un lugar terapéutico: proyecciones, simbologías, comunicación con uno mismo y los demás se encontrarían en un espacio de seguridad, provocación y percepción llamado instalación. Tal y como dice Vásquez (2013) "las instalaciones parecen una prueba más de la tendencia terapéutica del arte de exorcizar nuestros demonios haciéndoles frente por medio de montajes, sobre todo de objetos reales, de proyectos de obra, resoluciones y otros actos psicomágicos que también podemos calificar de hondo y sustantivo efecto espiritual".

Es precisamente el carácter híbrido y las posibilidades psicoexpresivas de la instalación lo que abre un campo de actuación y retroalimentación entre arte y terapias de expresión artística: Si la instalación es la suma de lenguajes artísticos, las terapias de expresión artística son la suma de recursos y técnicas propias de disciplinas como la musicoterapia, la danzaterapia, la arteterapia, la dramatización o el psicodrama, entre otras. En estos contextos terapéuticos se hace necesaria la interconexión de lenguajes y medios para atender las necesidades del paciente. Brucsia (1997) se plantea las siguientes cuestiones:

Cuando los ritmos visuales o táctiles son utilizados para estimular a clientes con impedimentos motóricos, ¿su experiencia se puede calificar como musical? Cuan- 
do discapacitados auditivos oyen sólo ciertas bandas de frecuencia de una composición grabada, ¿es su experiencia auténticamente musical? Cuando el cliente responde a la música a través de imágenes visuales o movimientos corporales, ¿son sus respuestas musicales o van más allá de sus límites? (p.25).

El debate abierto por los profesionales de la arteterapia sobre sus campos de actuación parece que tiende a adoptar una postura abierta en lo que se refiere a disciplinas artísticas. Domínguez (2005) dice: "La amplitud del concepto (si abarca todas las modalidades artísticas o sólo las artes visuales) invita a adoptar, precisamente en esta fase estructural del desarrollo de la disciplina, una óptica globalizadora" (p.6). Esta globalización ha derivado en una inconcrección en cuanto al uso de diferentes disciplinas artísticas y, como consecuencia, una libertad de actuación en ámbitos terapéuticos. De esta manera, en las terapias de expresión artística cualquier lenguaje artístico, verbal, musical, plástico, fotográfico o dramático, está al servicio del terapeuta y del usuario. Rogers propone que "las artes del movimiento, lo visual, lo sonoro y la relación creativa son lenguajes del alma y el espíritu que pueden aprovecharse para explorar el rango de las emociones humanas y permiten desarrollar un sentido positivo del self' (Guadiana, 2003, p.3).

Desde aquí se plantea que utilizar la instalación como recurso terapéutico, más allá de sus implicaciones artísticas, facilita la hibridación entre terapias de expresión artística de un modo intergrador.

\section{La instalación: El usuario dentro de la obra.}

La instalación no puede ser entendida sin la brecha abierta por Duchamp y sus ready-mades. La desacralización del objeto artístico conllevó una búsqueda de caminos que oscilan entre lo cotidiano y el concepto como arte. La reivindicación del poder expresivo de las cosas al mismo tiempo que la indiferencia hacia el objeto artístico, trasladaron el objeto de arte al terreno de la idea. Los planteamientos del dadaísmo y el arte conceptual, marcado por Duchamp, daban el pistoletazo de salida de Fluxus en Alemania, del Grupo Gutai en Japón, de la poesía concreta, así como del legado sonoro de John Cage y de todas las variaciones dadaístas, surrealistas y neodadaístas de los años 50.

De este modo, podría decirse que la instalación es consecuencia de varios factores: la desacralización del objeto artístico, el conceptualismo y el arte como idea o proyecto, las derivaciones del ready-made tales como los ensamblajes y las implicaciones espaciales de la escultura minimalista con el espacio expositivo y, por otro lado, el arte acción con la performance y el happening.

La instalación artística (...) se sitúa en esa corriente de expresiones artísticas antiobjeto que aparecieron a partir de los años 60. Tiene influencias directas del arte de acción, el performance, happening y body art. Contiene aspectos del arte povera, el arte conceptual, y con más evidencia elementos del land art, hasta el punto de ser realmente difícil diferenciar dónde empiezan unos y dónde terminan los demás. La instalación, como disciplina híbrida, está configurada por diversas referencias; incluye arquitectura y performance en su parentesco, y también contiene diversidad de caminos de las artes visuales contemporáneas. (Oliveira, Petry y Oxeley, 1994, p 7.) 
Larrañaga (2001) al referirse a la instalación como una de las rupturas artísticas, entiende que éstas "abarcan desde la apertura del universo artístico y su conexión con la práctica vital de cada uno, hasta una nueva implicación del público en el entramado artístico, lo que incorporaba relaciones absolutamente novedosas al proceso creativo" (p.25). Por lo tanto, la instalación es entendida como una intervención en interacción con el espectador, el cual será en última instancia, el explorador del hecho artístico. Como nos recuerda Vázquez (2015), "las nuevas formas de arte trasladan al espectador el sentido de la obra" (p.272), algo ya apuntado por Umberto Eco en Obra abierta y que plantea el significado de la misma dependiendo de la interpretación que haga no el emisor, sino el destinatario, que es el que confiere el verdadero sentido a la obra (Vázquez, 2015). Los medios para conseguir los fines artísticos son ilimitados. En ocasiones, el proceso vence al resultado, la acción vivencial vence a la obra y lo efímero rompe con el estatismo del museo. En estos casos, el individuo es protagonista activo y el objeto artístico pasa a ser una herramienta más dentro de un lugar enmarcado en un panorama de libertad expresiva e interacción de lenguajes. La aportación activa del público en la obra de arte y sus posibilidades creativas, colocan en el centro de la historia al espectador.

En este contexto artístico y en el terapéutico expresivo, el proceso puede plantearse como re-creación en sí mismo, tanto en el uso de los materiales como de las acciones llevadas a cabo. Es a través de estas acciones, donde la sensorialidad, la expresión y la relación intra e interpersonal, adquieren una fuerza entendida como necesidad interior.

El espacio, la luz, el sonido, los objetos, el propio cuerpo, son algunos de los elementos mediadores comunes a la instalación y a las terapias expresivo-creativas; sus posibilidades simbólicas, comunicativas y expresivas, dentro de una dimensión psicológica, hacen del concepto instalación una apertura a lo inexplorado. El abanico de posibilidades es tan abierto como la situación, el momento, la circunstancia vital o la realidad del usuario. El terapeuta expresivo, del mismo modo que el artista de instalación, brinda mediante la hibridación de diferentes medios artísticos, un espacio a la interpretación, a la sensorialidad y a la vivencia para facilitar la transformación, es decir, en la propuesta planteada el paciente ocupa el lugar del expectador, pasando a ser protagonista de la acción dentro de una instalación con fines terapéuticos.

\section{Sinergias entre instalación y terapias de expresión.}

Este estudio nace del interés por indagar en las posibilidades de la instalación como recurso terapéutico más allá del ámbito puramente artístico. Para ello, en las sesiones arteterapéuticas planteadas más adelante, se eliminan las connotaciones estéticas que pueda poseer la instalación en relación a sus cualidades artísticas. De este modo, se analizan los elementos componentes de la instalación desde un punto de vista arteterapéutico, en donde el juicio estético no tiene cabida, se promueva la libertad de acción y donde se crea un espacio de contección y acompañamiento respetuoso.

El análisis de los factores potencialmente terapéuticos que contiene una instalación se fundamenta en los principios planteados por Ilyan Kabakov en relación al concepto de instalación total y, por otro lado, se recurre a diversos artistas que plantearon instalaciones que ellos denominaron terapéuticas: Louise Bourgeois, Lygia Clark o Turrell (Fig. 1).

La interconexión existente en cuanto a lenguajes artísticos entre instalación y las terapias de expresión artística, se define en relación a aspectos tales como el espacio, 
siendo el lugar arquitectónico de transformación y de relación gestáltica, el tiempo, planteado como acción en la experiencia, los objetos que ésta alberga, la luz y su repercusión perceptiva y, por último, el sonido que como material intangible, forma parte sensorial y contribuye a la concepción espacial de la obra.

A la hora de trasladar los elementos vinculados a la instalación, espacio, luz, sonido, elementos y tiempo, en un espacio acotado para la terapia, encontramos los espacios multisensoriales snodheguel que tienen como objetivo, potenciar todas las entradas sensoriales (ojos, oídos, nariz, boca, piel) (Cid y Camp, 2010), mediante proyecciones de colores, sonidos o aromas, generalmente con un material estandarizado. Promueven la relajación, potencian el autocontrol e incentivan la exploración y el desarrollo de capacidades creativas. Además, establecen una buena comunicación con el personal que conduce la sesión y proporcionan una situación de ocio y bienestar. Por otro lado, aumentan el nivel de concentración y de atención además de reducir las alteraciones de conducta (Cid y Camps, 2010). Si bien estos espacios no tienen el componente artístico, de hibridación de lenguajes y libertad creativa que se plantea en las sesiones expuestas, sí que pueden proporcionarnos datos empíricos sobre beneficios terapéuticos en cuanto a espacios acotados para la interacción y la estimulación sensorial dentro del ámbito de las terapias expresivas.

Estos referentes y otros, cuyos planteamientos artísticos, dentro de la instalación, tienen un sentido evidentemente psicoexpresivo, son las claves para la sistematización de aspectos teóricos y terapéuticos en las que se sostienen experiencias arteterapéuticas, fundamentadas en el uso de esta disciplina artística.
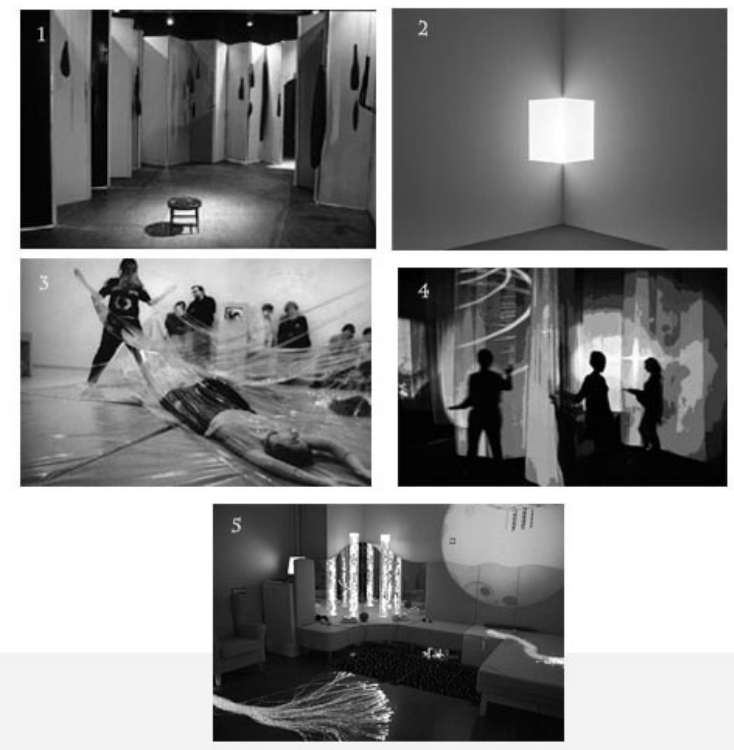

Figura 1. Referentes artísticos y conceptuales. 1) Louise Bourgeois. Articulated Lair, 1986 de magiciensdelaterre.fr/artistes.php?id=46. 2) James Turrell, Afrum I (White), 1967 de http://web.guggenheim.org/exhibitions/turrell/ 3) Lygia Clark. Arquitecturas biológicas, 1969 de https://es.pinterest.com/ pin/345862446353623910/4) Pipilotti Rist. Partit amistós-sentiments electrònics, $2011 \mathrm{de} \mathrm{http://www.huffingtonpost.co.uk/2011.} \mathrm{5)Sala} \mathrm{snodheguel} \mathrm{de}$ www.google.es/search?q=sala + snoezelen\&tbm. 


\section{Espacio}

El concepto de instalación está estrechamente vinculado al espacio donde se encuentra. Este espacio se expande y se acota física y sensorialmente. El espacio expositivo pasa a ser un espacio para la participación activa del espectador como "fenómeno de transición, tanto si está ocupado por un objeto como por una acción, lo importante es su carácter ilusorio" (Winnicott, citado por Schneider, 1993, p.193). De igual manera, a la hora de aplicar terapias de expresión mediante la instalación, el espacio adquiere un carácter de lugar terapéutico. Este factor está ejemplificado en el espacio arquitectónico del que habla Louise Bourgeois; sus instalaciones son creadas para el control de sus propios recuerdos del pasado, la propia artista dice: "cuando empecé a construir las Cells, quería crear mi propia arquitectura, y no depender de un espacio de museo, no tener que adaptar mi escala a él. Quería construir un verdadero espacio en que uno pudiera entrar y pasear por él" (Colomina, 1999, p.43). La configuración de las instalaciones de esta artista, dan forma a elementos del pasado, "las crea para olvidar el pasado, para derrotarlo, revivirlo y hacer posible que el pasado se olvide." (Colomina, 1999, p.44).

Otro factor a tener en cuenta es el del juego como base arteterapéutica a la hora de desarrollar los procesos de intervención-acción. Según esta consideración, el espacio puede responder a unos parámetros creativos en el sentido lúdico que plantea Freud, teniendo en cuenta que para él "el proceso creativo del artista se deriva de la acción lúdica y no de un sofisticado proceso intelectual” (Coll, 2006, p.152).

Atendiendo a la consideración del espacio a la hora de desarrollar una sesión terapéutica, sirva de ejemplo una de las experiencias que nosotros hemos podido llevar a la práctica mediante el juego. En una de las sesiones arteterapéuticas llevadas a cabo para niños y niñas con diversidad funcional, el espacio fue transformado en instalación (Fig.1). En este caso, los principios lúdicos fueron la base del espacio de la instalación para la estimulación sensorial y el juego mediante diferentes elementos mediadores (círculos, papel y luces de diferentes naturalezas) con los que se pretendía potenciar las vías de comunicación de los usuarios. El espacio estipulado fue el agente intermediario para el desarrollo de las acciones de los niños y niñas, a través de su carácter ilusorio y sus elementos estimuladores. A través de las acciones los usuarios encontraron, tal y como dice Abad (2008) un espacio lúdico de relación con uno mismo y con los demás:

Cada instalación suscita un nuevo paisaje para la "coreografía" de los niños y niñas en su libre movimiento, (...) En el espacio ofrecido se producirán juegos, relaciones, posibilidades, imaginarios, situaciones, acontecimientos, narraciones y nuevas significaciones como proyecto compartido (p.174).

Además de alcanzar el objetivo lúdico perseguido, los usuarios mediante esta sesión terapéutica, exploraron posibilidades de movimiento y estimularon los canales sensoriales, al tiempo que exploraban posibilidades de interacción con el espacio estipulado. 

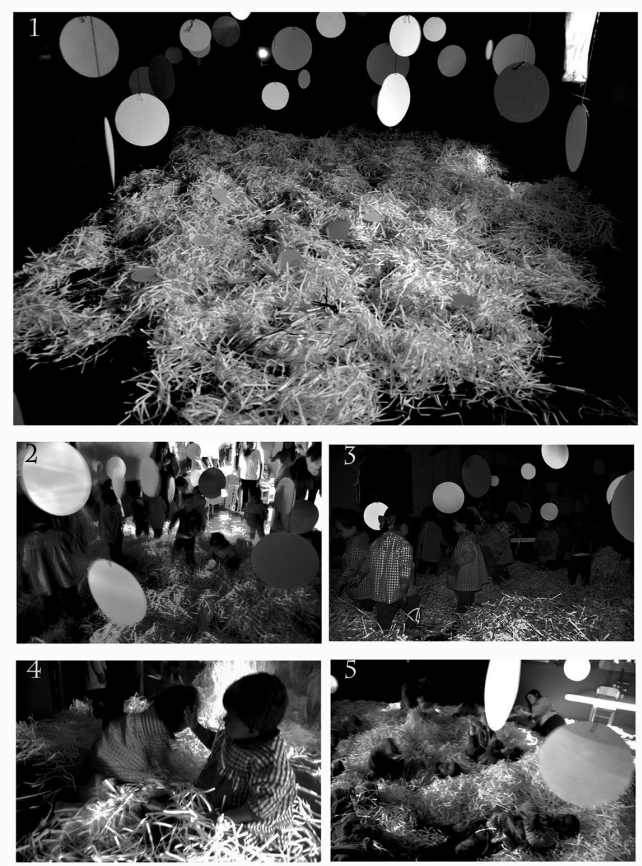

Figura 2. Terapia de estimulación sensorial con niños con diversidad funcional. Centro de atención temprana L'Alquería (Valencia) desarrollada en noviembre de 2016. 1) Planificación del espacio. 2) Entrada al espacio en base al concepto de Kabakov. 3) Momento de expansión en la instalación. 4) Niño con déficit cognitivo reconociendo su mano y estableciendo relaciones con los efectos luminosos. 5) Finalización de la sesión mediante la vuelta a la calma. Fuente propia.

Kabakov (2014) analiza el espacio físico y psicológico de la instalación y los elementos determinantes que pueden potenciar o anular diferentes sensaciones. En su estudio, expone la repercusión psicológica, simbólica y sensorial de cada parte del espacio acotado por y para una instalación. Según él, los muros tienen un papel definitivo en la sensación que tiene el espectador dentro del espacio. Nos separan del mundo externo y además "parecen ser la orilla del mundo de la instalación real, el cual funciona siempre como un universo completo, como un modelo autónomo, completo" (Kabakov, 2014, p. 30). El artista plantea la importancia de muros sin ventanas, de este modo, la ilusión generada por la obra sería destruida por la información del exterior. Esta concepción de escenario teatral cerrado confiere a la instalación un carácter ficticio y de irrealidad.

El techo desempeña el papel de "cielo, en todo el cosmos de la instalación total" (Kabakov p.30). La altura del techo puede provocar y variar, produciendo sensaciones de opresión si un techo es bajo, o la sensación de libertad si es alto. El piso, se interpreta a nivel subconsciente como la tierra. La entrada y la salida de una instalación, representa la transición a ese mundo, una transición, según Kabakov "llena de significados, una puerta común, como símbolo de prohibición o permiso para entrar, creará el choque para el que entre como foráneo" (p.31). La entrada de la instalación 
plantea en los niños y niñas un tránsito a un mundo ficticio, estimulante, donde el cielo es metáfora de un cielo con círculos de colores brillantes y el suelo un lugar donde sentir diferentes sensaciones táctiles y visuales (Fig.2).

En este sentido, el espacio de seguridad propuesto a través de la instalación referida anteriormente, dentro un encuadre terapéutico, fue un lugar que suscitó la intervención y la acción, en donde la estimulación de los sentidos y la configuración de relaciones inter e intrapersonales se generó en un espacio diseñado como una instalación de atmósfera irreal. Tanto el terapeuta expresivo como los usuarios se aproximaron y permanecieron en él en espera de una respuesta o una transformación. En este punto cabe tener en cuenta, no únicamente los objetivos terapéuticos, sino además, las diferencias entre los usuarios ante la aproximación y valoración del espacio, los elementos materiales e inmateriales y todo lo que en él sucede.

\section{Tiempo.}

Tal y como dice Kabakov (2014), la instalación, al igual que le sucede al teatro, la danza, la música y el cine, pertenece a la familia de las artes temporales. En este sentido, la crítica de arte Anne-Marie Duguet apunta que, desde mediados del siglo XX "el tiempo aparece no sólo como un tema recurrente, sino como un parámetro constitutivo de la naturaleza propia de una obra de arte" (Rush, 2002, p.12). Kabakov (2014) dice sobre la dimensión temporal en la obra de arte tipo instalación:

El tiempo fluye a través del espectador favoreciendo el encuentro con una obra de arte que el espectador experimenta subjetivamente; algo que virtualmente se apodera físicamente de él desde el interior y resulta un componente extremadamente necesario de la percepción en la obra de arte (p.67).

La apreciación temporal dota al usuario de tiempo para la contemplación, la acción o la estimulación. Mareduelo (1995) dice sobre el acontecimiento temporal en una instalación: "los vínculos establecidos entre los happening, las instalaciones y environments (...) sustituye la acción dramática por la acción sin más calificativos que se soporta y desarrolla en un espacio" (p. 69). Tal es el caso de la bailarina Pina Bausch, sus coreografías existen y se desarrollan en consonancia a un espacio de instalación lleno de elementos que son manipulados en una hibridación entre la danza y la acción. La danza-teatro de esta creadora acontece en un escenario que ha perdido su tradicional forma para dar paso a una instalación donde confluyen luz, espacio y tiempo, música, ruido, silencio o color. El espectador participa del desarrollo y catarsis de las acciones a diferentes niveles sensoriales, cognitivos y sociales.

La sensación de acontecimiento que transcurre en el espacio de la instalación adquiere más relevancia si cabe en las videoinstalaciones. Éstas permiten que el usuario amplie la exploración del tiempo, "con un vídeo y un monitor, las posibilidades se multiplican de manera espectacular, en las videoinstalaciones en las cuales se utilizan varios monitores o superficies de proyección” (Rush, pp. 116-117). En este sentido Pipilotti Rist crea espacios virtuales para la participación mediante proyecciones de imagen, de vídeo y de sonido. Esta artista se esfuerza en introducir al espectador en un ambiente onírico dentro de las proyecciones, permitiéndole en 
ocasiones abrir los sentidos a estímulos perceptivos y en otros casos, exponiéndolo a estados de alerta y de reflexión personal.

En nuestro caso, para una sesión llevada a cabo dentro del contexto de la educación infantil inclusiva, se planteó una instalación que pretendía crear una atmósfera de ensoñación por medio de proyecciones y sonidos de la naturaleza. El objetivo fue establecer relaciones estimulantes entre los usuarios y el espacio. El tiempo de permanencia en la instalación suscitó todo tipo de acciones y reacciones con las imágenes y el sonido. Los usuarios se movieron, actuaron y generaron relaciones con las proyecciones cambiantes, con ellos mismos o con los otros. Mediante movimientos expansivos, ahondaron en sus posibilidades psicomotrices o, por el contrario, de autocontrol, con el fin de potenciar la concentración. (Fig.3).
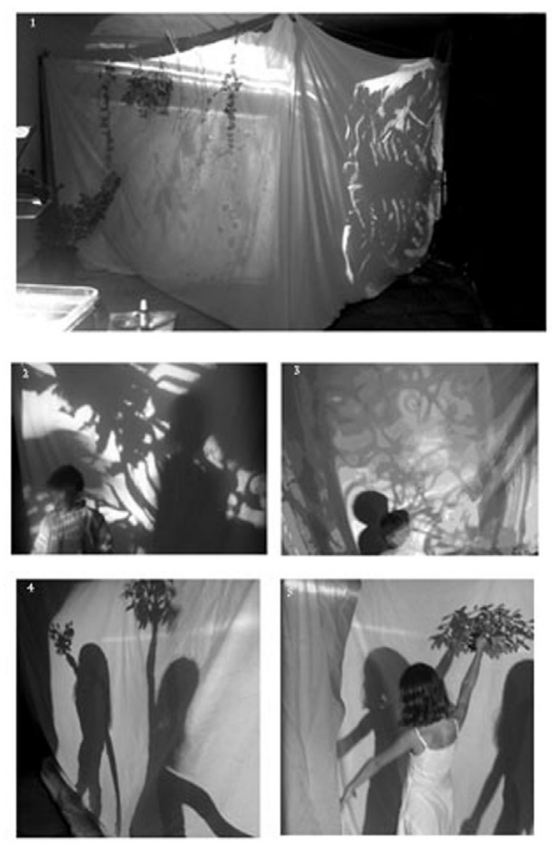

Figura 3. Sesión arteterapéutica con niños y niñas con diversidad funcional en el Centro de atención temprana L'Alquería (Valencia) desarrollada en mayo de 2016. 1) Planteamiento general externo de la instalación. 2) En esta imagen podemos apreciar la interrelación con las proyecciones de tierra sobre caja de luz que generó en el usuario movimientos expansivos. 3) Usuario con déficit de atención en un momento de atención y autocontrol suscitado por la proyección realizada con líquidos. 4 y 5) Niñas moviéndose con los sonidos de la naturaleza experimentando con su sombra y la de su compañera. Fuente propia.

Las vinculaciones entre la danza-teatro, el happening, la performance, la danza-terapia, el teatro terapéutico y las videoinstalaciones, abren caminos a relaciones y aplicaciones arteterapéuticas en el espacio de la instalación. 


\section{Objetos.}

Los objetos y los materiales crean todo un complejo mundo de significados en el espacio de la instalación y de la terapia de expresión. En un contexto terapéutico, los objetos de una instalación funcionarían como "objetos transicionales" (Winnicott, 1997, citado por Coll, 2006, p.163) que crearían una nueva realidad en un lugar de seguridad. Los objetos serían puentes entre el conflicto, el sueño o el deseo y posibilitarían "poder nombrar las cosas, poder desplazar, metaforizar. Es una procura de sentido, una representación en nombre de otra cosa” (Coll, 2006, p.164).

Dentro de un escenario psicodramático se suele disponer de un mínimo de mobiliario y de elementos. Cuando no se dispone de ellos, los elementos simbólicos o imaginarios son el "como si" en que se desarrolla la representación. De esta manera en una instalación, los objetos actúan como intermediarios y, por lo tanto, pueden ser facilitadores de la comunicación inter e intrapersonal, sirviendo de mediador, en la relación paciente-terapeuta, actuando como nexo de unión en el triángulo terapéutico.

La artista Lygia Clark llama a los objetos y materiales que esparce por la estancia donde se da lugar la instalación "objetos relacionales". La propia artista dice: "En estas primeras instalaciones el hombre reencontraba su propio cuerpo a través de sensaciones táctiles producidas por los objetos exteriores a él" (Borja-Villel, 1998, p.247). De este modo, pretende que el espectador se convierta en paciente de una terapia a través del arte.

Clark estaba convencida de que revitalizando el campo del arte mediante las técnicas psicoterapéuticas, los individuos podrían reinventar su propia existencia. Con los Objetos relacionales, su última obra, la artista se acerca todavía más a su objetivo. Pequeñas bolsas de plástico o tela llenas de aire, de agua, de arena o poliestireno; tubos de caucho, rollos de cartón, trapos, medias, conchas, miel y otros muchos objetos inesperados se desparramaban en el espacio poético que creó en una habitación de su casa y que denominaba "consultorio". Se trataba de los elementos de un ritual iniciático que la autora instauró a lo largo de "sesiones" regulares con cada receptor (Borja-Villel, 1998, pp.13-14).

En nuestro caso, con el fin de desarrollar terapias de expresión artística dentro del ámbito de la Educación social (Fig. 4), se hizo uso de la idea de utilizar objetos transicionales (Winnikot) u objetos relacionales (Clark) como agentes intermediarios. En concreto se utilizaron máscaras neutras blancas, como elementos de neutralización de los gestos faciales, que suscitaron movimentos corporales expresivos en cada uno de los usuarios. Las telas de plástico volátil pertenecientes a la instalación que se presenta, invitó a la interrelación, cooperación y relación para la cohexión grupal y la exploración en las capacidades expresivas propias y del grupo. Tal y como concluyeron los estudiantes, percibieron el escenario como un lugar que tenía vida. Destacaron de la experiencia los aspectos orgánicos y al mismo tiempo frágiles que la instalación les suscitó, lo que según ellos provocó, en colaboración con la música, reacciones de exploración corporal, propias pero sobre todo de grupo. Apuntaron también que no podía ser de otro modo, porque estaban en un mismo lugar, peculiar según ellos, que les hizo sentirse unidos para la acción.

Respecto a otro de los elementos mediadores, la máscara, algunos estudiantes apuntaron que sintieron pérdida de identidad propia, pero que les hizo potenciar su 
sentimiento de pertenencia al grupo. Para otros, la máscara les fortaleció y les invitó a ser guías del resto de los compañeros. Las telas de plásticos hicieron el resto.
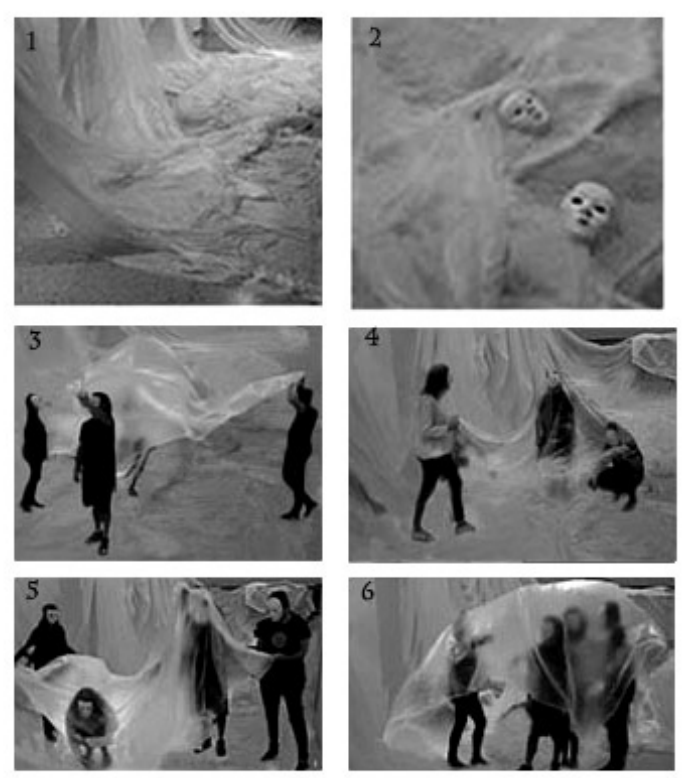

Figura 4. Sesión terapéutico-expresiva con estudiantes de Educación social llevada a cabo en 15 de febrero del 2017. 1) Presentación general de la instalación. 2) Detalle de las máscaras neutras que fueron elegidas por libre elección de los usuarios. 3) Los estudiantes estableciendo primeros contactos con uno de los plásticos de la instalación. 4) Momento en el que los usuarios eligen entrar en la tela 5) Usuaria entrando en las telas volátiles de plástico. No todos los participantes entraron debajo del elemento pero todos cooperaron por tratar cuidadosamente tanto a lo compañeros que entraban como al frágil material. 6) Uno de los momentos en los que los participantes entraron en grupo en las telas plásticas. Fuente propia.

Ahondando en el sentido terapéutico de los objetos en una sesión arteterapéutica, se encuentran evidentes relaciones con el objecte trouvé planteado por Marcel Duchamp. Éste puede ser entendido como objeto o elemento intermediario pasando a ser símbolo o proyección en una sesión arteterapéutica. La manipulación de los medios, tal y como dice López (2011) establecería en el paciente "un diálogo intuitivo y sensitivo con los materiales que van dando forma a su autoexpresión" (p.185). A este respecto Coll (2006) plantea que:

El Objecte trouvé no tiene un orden establecido, es el azar el que hace que varios objetos se relacionen, se encuentren y emerja algo que impacta en el espíritu del artista y lo considere su obra. Esta obra aparece por casualidad, nunca en el sujeto; en el artista no ha habido un fin preconcebido, la obra ha surgido del azar, en el momento que la unión o dispersión de objetos ha ocasionado el impacto espiritual del sujeto. El objecte trouvé se convierte en algo encontrado y cambiado 
por casualidad en una elección promovida por estructuras psíquicas impulsoras de vivencias. (Duchamp citado por Coll, 2006, p.162)

El mensaje dadaísta, tal y como lo desarrolla Duchamp, es planteado por Scheneider (1993), como análogo al mensaje del psicoanálisis y al proceso creativo, siendo el concepto de azar o de casualidad otro medio de acceso al subconsciente. Por lo tanto, el objeto será entendido como interpretación subjetiva, a través del cual pueden surgir significados y evocaciones distintas.

Alrededor del objeto encontrado, se planteó una propuesta terapéutico-expresiva a través de la instalación, llevada a cabo con un grupo de mujeres que pretendían una mejora en aspectos sobre el autoconocimiento. Esta sesión arteterapéutica planteó la instalación como lugar de celebración, ritual y participación. El espacio configurado para las usuarias fue utilizado para el conocimiento personal y del grupo. A modo de metáfora de movimiento, cambio y transformación, se utilizó la simbología del árbol como ser vivo en constante crecimiento.Los objetos dispuestos por la sala actuaron como objetos transicionales que suscitaron proyecciones personales. En la sala donde se desarrolló la sesión arteterapéutica, se dispusieron tres estructuras escultóricas con forma de árbol. Cada uno de los árboles fue destinado a albergar tres tipos diferentes de elementos: Objetos, palabras e instrumentos musicales. El espacio, los árboles y los elementos fueron el anclaje de la instalación y pretendieron propiciar un lugar para el desarrollo de la acción. La música acompañó a la acción y al movimiento, el cual condujo, en un primer momento, a elegir el objeto/s y después colgarlo de las estructuras que simbolizaban las ramas. Una vez colgados los objetos y tomando cierto distanciamiento, se plantearon preguntas que hicieron referencia a la interpretación posterior sobre los objetos elegidos, las relaciones establecidas entre ellos y el lugar que decidieron ocupar.

\section{Luz.}

Según Kabakov (2014) la luz participa en la creación del ambiente. Este artista analiza diferentes tipos de luz para crear atmósferas, simbologías o dotar de protagonismo a elementos que participan en una instalación:

Luz brillante, media luz, media oscuridad, luz que consiste en focos iluminando un solo objeto y, finalmente, un foco que ya por sí solo es a menudo algo totalmente expresivo (...) es difícil sobrestimar la importancia de la luz en la instalación total como un medio para crear una atmósfera especial de recuerdos, de imaginación, sobre todo cuando estamos hablando de luz semiapagada. En las instalaciones alargadas (corredores, suites) la luz guía al espectador, en otros casos concentra su atención o la dispersa, la luz puede crear un confort íntimo o la locura de un manicomio (Kabakov, 2014, p.54).

El artista James Turrell estudia los modos de percepción del espectador mediante sus instalaciones de luz y espacio:

La luz se presenta como un objeto de reflexión que requiere el máximo rigor científico que ha llevado a Turrell a convertirse en un experto físico, psicólogo, e incluso astrónomo. En palabras del artista, la luz destaca por su carácter de thingness 
que le permite indagar en el funcionamiento óptico del ojo del espectador y su percepción a través del cuerpo. (Paulo, 2011, p.202)

Una instalación de Turrell existe como una aparición proyectada por nuestra actividad visual y nuestro sistema nervioso más que como un objeto fijo. En lugar de los espectadores reflexivos "este arte tiende a efectuar una especie de experiencia sublime en la que el espectador se ve abrumado por una aparición que él parece proyectar en el ser" (Foster, et al., 2006, p.654. A este respecto, James Turrell dice sobre la naturaleza de sus instalaciones:

Mi trabajo trata sobre el espacio y la luz que lo habita. Trata sobre la forma en que te confrontas e indagas el espacio. Trata sobre tu forma de ver. Cómo llegas a él es importante. Las cualidades del espacio deben verse, y la arquitectura de la forma no debe ser dominante. Estoy realmente interesado en las cualidades de un espacio que descubre a otro. Es como mirar a alguien que está mirando. A medida que indagas un espacio con la visión, es posible verte a ti mismo viendo. Esta visión, esta indagación, imbuye el espacio con la conciencia. En función de la forma en que decides verlo y dónde te encuentras en relación a éste, creas su realidad. (Turrell citado por Paulo, 2011, p.202).

Las sesiones arteterapéuticas propias planteadas anteriormente (Fig.2 y Fig.3), presuponen la indagación de un espacio lumínico que introduce al usuario en un lugar para la estimulación de los canales sensoriales, provocando reacciones tales como la relajación, el movimiento o la autoregulación, pero sobre todo, la potenciación de su propia concepción. Proponer espacios en donde se vivencien situaciones y estímulos sensoriales potencia la creatividad, la comunicación y la exploración del conocimiento interior y exterior. De este modo, el estímulo de los sistemas perceptivos proporciona mejoras a distintos niveles.

\section{Sonido.}

Integrar sonidos en una instalación complica el papel perceptivo del usuario y altera el espacio arquitectónico de una instalación llegando a reemplazar el propio sentido de espacio y ubicación de los espectadores. La voz, la música, el ruido o "el propio silencio en las instalaciones, funcionaría como el espacio no ocupado, cobrando tanta significación como el espacio ocupado y, de esta manera, convirtiéndose así todo el espacio en escultura" (Rose, citada por Maderuelo, p.69).

La manipulación del estado de ánimo del espectador por medio de la música está ejemplificada en instalaciones, videoinstalaciones y eventos totales intermedia. En este tipo de instalaciones el espectador parece ser un viajero en un espacio configurado por voces, sonidos o ruido; tal es el caso de obras, entre otras, como La mente se detiene (1991) de Bill Viola. En esta instalación compuesta por cuatro pantallas de proyección, una voz casi inaudible murmura frases sobre el cuerpo y la pérdida de sensación mientras las imágenes (sobre paisajes de la naturaleza) culminan con estallidos de sonido acompañando el movimiento de las imágenes, de manera que el espectador experimenta nuevas formas de percepción (Rush, 1999) en un "intercambio de papeles entre el plano acústico y el visual” (Kabakov, 2014, p.105). Este acto de control sobre las emociones puede suscitar confusión, rebelión o reflexión pero, en cualquier caso, generaría procesos de cambio.

En un encuadre terapéutico la conciencia periférica del usuario sería afectada en un espacio por factores tales como el volumen del sonido, cambios repentinos, 
voces o susurros, narradores, voces cotidianas o sonidos de la naturaleza. El usuario, de este modo, se vería afectado por un espacio lleno por el sonido, en donde el impacto podría ser "tonal, mental, ideológico y físico" (Kabakov, 2014, p.109). Tal fue el caso de la sesión psicoexpresiva que pudimos llevar a cabo, en cuya puesta en práctica se aprovechó del anonimato que la sombra provoca para evocar metáforas córporales mediante la proyección de elementos con los que los estudiantes desarrollaron movimientos relacionales. Las fases del proceso produjeron movimientos generados por la recepción de la música, los silencios, los elementos y las luces y sombras (Fig. 5).

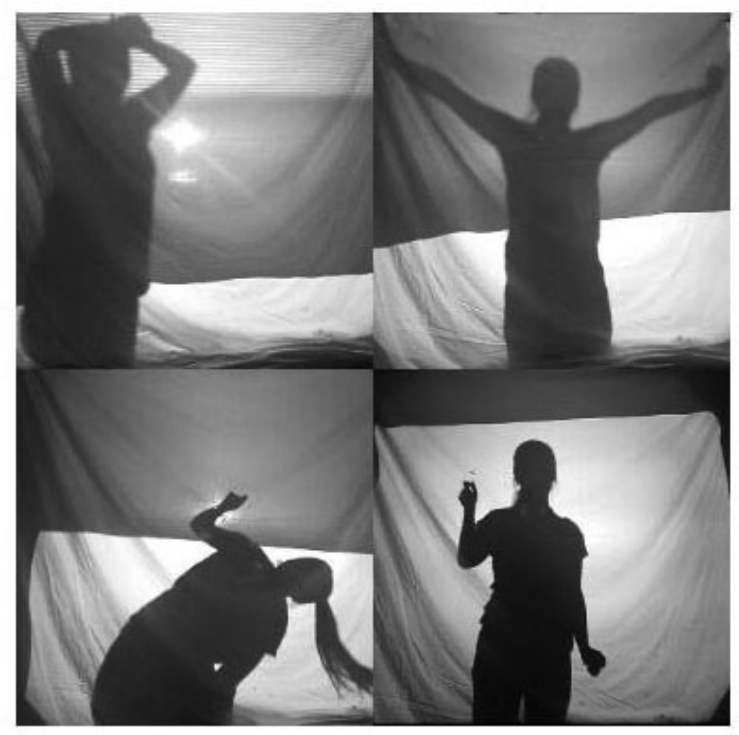

Figura 5. Sesión psicoexpresiva en un espacio acotado como instalación lumínica con estudiantes de Educación social. Enero 2017 A través de estas imágenes de la experiencia, podemos observar diferentes momentos de la acción que suscitó en una usuaria relaciones expresivas con las proyecciones sobre telas que iban transcurriendo. Las reacciones ante los cambios de luz, sombras, colores, sonidos, música y silencios, provocaron movimientos expansivos en ocasiones y en otros simbólicos. La dramatización fue gestual, sin necesidad de la palabra. La usuaria expresó e interaccionó con el resto del grupo. Fuente propia.

En dicha sesión, los procesos terapéuticos planteados con los elementos expuestos, estaban enfocados a establecer con el usuario conexiones con el inconsciente, que en este caso, llevaron en unos momentos a la introspección y en otros al movimiento relacional con la música. Tal y como la usuaria, estudiante de Educación social dijo: "El espacio, la luz y el sonido, me condujeron a la libre expresión del movimiento". Dicha usuaria expresó en la reflexión final, que estos elementos, en un espacio acotado, le permitieron experimentar las posibilidades del movimiento y la exteriorización de sentimientos (Fig.5). 


\section{Conclusiones}

El espacio de la instalación ha sido expuesto como lugar acotado de intervención y acción transformadora, entendido como configurador de vivencias musicales, plásticas, de movimiento y danza, así como de escenario de experiencias psicodramáticas. Podemos afirmar que aquellos elementos característicos de las expresiones artísticas fundamentadas en la instalación con fines terapéuticos pueden tener resultados positivos en aplicaciones arteterapéuticas.

En este sentido, hemos comprobado a través de las propias experiencias, que la realización y acomodación del espacio de la instalación debe ser flexible por parte del arteterapéuta, que debe tener en cuenta, para sus sesiones diferentes, aspectos tanto en cuanto a recursos y espacios de los que se dispone, como a diferentes registros terapéuticos a utilizar en cada caso. Además, más allá de los planteamientos estéticos de la instalación como género artístico y considerando que este factor no debe descuidarse, éste deviene en la arteterapia en un objetivo secundario. Lo realmente importante es que el usuario encuentre en la instalación un espacio que invite a profundizar en la relación consigo mismo y con los demás, así como que pueda propiciar la estimulación de los canales sensoriales.

A través de los propios elementos que proporciona la instalación, los usuarios pueden conocerse, explorarse, expresarse, tranformarse y reconstruirse. De este modo, la instalación establecida como un espacio de seguridad y acompañamiento, ayuda a encontrar vías hacia un proceso personal de crecimiento y mejora.

\section{Referencias bibliográficas}

Abad, J. (2008). El placer y el displacer en el juego espontáneo infantil, Papeles de arteterapia y educación artística para la inclusión social, Vol.3/2008, pp.167-188. Madrid: Universidad Complutense de Madrid.

Borja-Villel, M.J. (1998). Lygia Clark. En M.J. Borja-Villel, N. Enguita y F. Figueiredo (Eds.), Lygia Clark (pp.12-14). Barcelona: Fundació Antoni Tàpies.

Brucsia, K.E. (1997). Definiendo musicoterapia, Salamanca: Amarú.

Cid, M.J y Camps, M. (2010). Estimulación multisensorial en un espacio snoezelen: concepto y campos de aplicación, SigloCero. Revista española sobre discapacidad intelectual, Vol 42 (4). Núm. 236, pp.22-32.

Coll, F.G. (2006). Proceso creativo y simbolización en la clínica del arteterapia. En F.G. Coll (Ed.) Arteterapia.Dinámicas entre creación y procesos terapéuticos, (151-176). Murcia: Universidad de Murcia.

Colomina, B. (1999). La arquitectura del trauma. En C. Ortega (Ed.), Louise Bourgeois. Memoria y arquitectura (pp. 29-51). Madrid: Museo nacional de arte Reina Sofía/Ministerio de Educación y Cultura.

De Oliveira, N., Petry, M. y Oxeley, N. (1994) The installation art. London: Thames and Hudson.

Domínguez, P. (coord.), (2005). Arteterapia. Principios y ámbitos de aplicación. Consejería de educación y ciencia de la Junta de Andalucía.

Foster, H., Krauss, R., Bois, Y.A., Buchloh, B. (2006). Arte desde 1900. Madrid: Akal. 
Guadiana, L. (2003). Las artes expresivas centradas en la persona: Un sendero alternativo en la educación y la orientación. Entrevista a Natalie Rogers. Revista Electrónica de Investigación Educativa 5 (2). Recuperado de http://redie.ens.uabc.mx/vol5no2/contenido-guadiana.html.

Kabakov, I. (2014). Sobre la instalación total. FrontGround\&ESAY: Yucatán.

Larrañaga, J. (2001). Instalaciones. Honrrubia: Nerea.

López, M. (2011). Técnicas, materiales y recursos utilizados en los procesos arteterapéuticos, Papeles de arteterapia y educación artística para la inclusión social, Vol. 6 (2011) pp. 183-191. Madrid: Universidad Complutense de Madrid.

Maderuelo, J., (1990). El espacio raptado. Madrid: Mondadori.

Paulo, M. (2012). El espectador desorientado: luz, espacio y percepción en las instalaciones de James Turrell, Bajo palabra. Revista de filosofía. II Época, $N^{o}$ 7, pp.195-206. Madrid: Universidad Complutense.

Rush, M. (2002). Nuevas expresiones artísticas a finales del siglo XX. Barcelona: Destino.

Schneider, L. (1993). Arte y psicoanálisis, Madrid: Cátedra.

Vásquez, A. (2013). Arte conceptual y posconceptual. La idea como arte: Duchamp, Beuys, Cage y Fluxus. Nómadas. Revista crítica de ciencias sociales y jurídicas, 37 (2013.1). http://dx.doi.org/10.5209/rev_NOMA.2013.v37.n1.42567

Vázquez, I. (2015). La interactividad como arte, Icono 14 Revista de comunicación y tecnologías emergentes (13), pp.270-293. doi:10.7195/ri14.v13i1.754 